\title{
NEWS
}

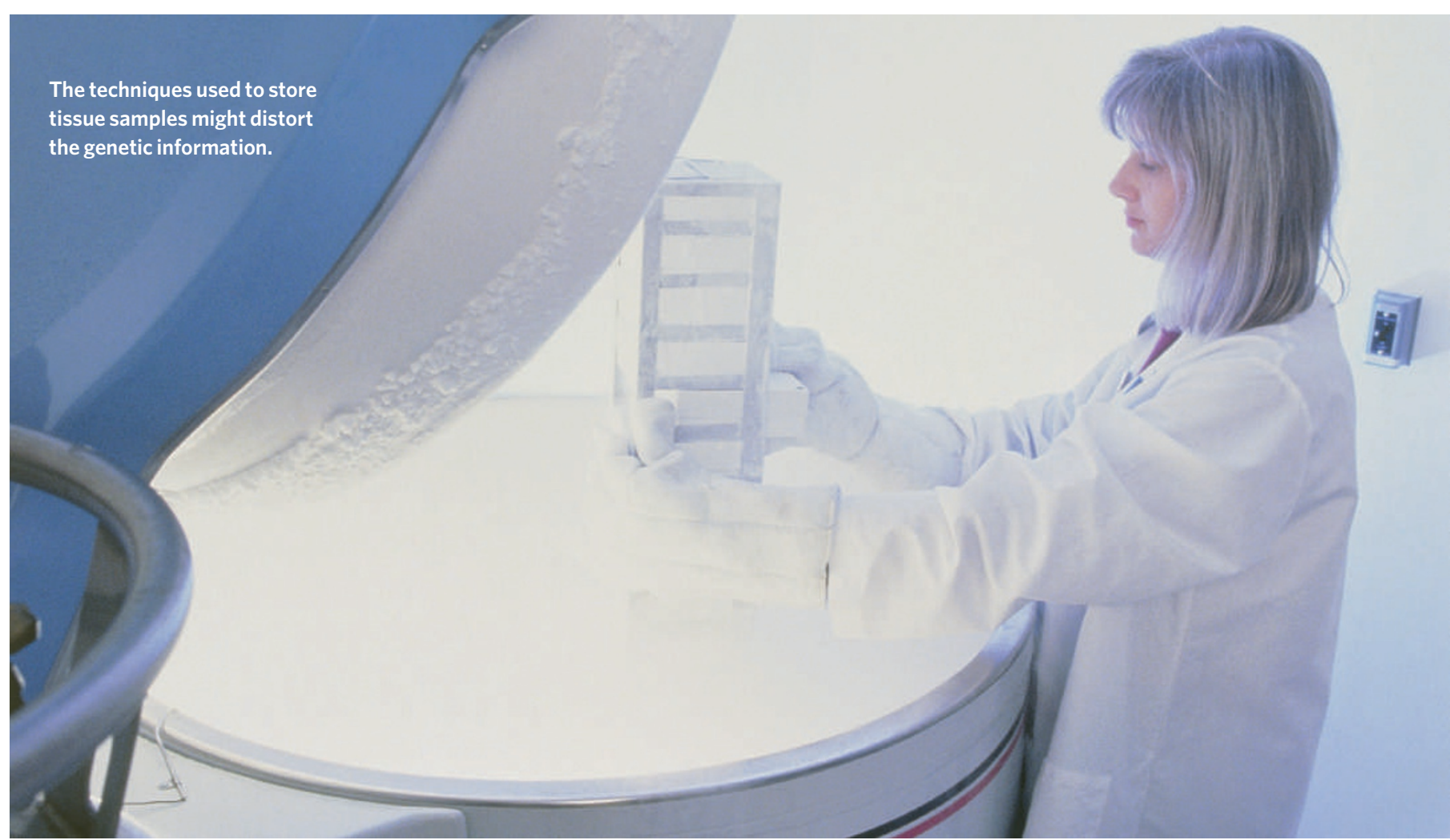

\section{Cancer atlas maps out sample worries}

America's National Cancer Institute (NCI) has confirmed that its much-heralded cancer genome atlas is off to a slow start. And scientists say that the obstacles facing the project are just a taste of those that will soon confront all researchers who use large-scale methods to analyse material from tissue banks.

Nine months ago, US National Institutes of Health director Elias Zerhouni announced the "scientific start" of the Cancer Genome Atlas, which aims to catalogue the genetic characteristics of various cancers at a previously impossible level of detail. The project was controversial even before it started, with some scientists afraid that it would divert resources from investigator-initiated research in tight budget times (see Nature 438, 894; 2005). But it prevailed, thanks in part to strong support from Francis Collins, director of the National Human Genome Research Institute (NHGRI) in Bethesda, Maryland.

Now, the NCI has confirmed that the project stumbled as soon as it left the starting blocks. The problem lies with brain-cancer samples, which are removed surgically from patients and stored at a tumour bank at the MD Anderson Cancer Center in Houston, Texas. The centre was chosen to provide the Cancer Genome Atlas with samples of glioblastoma multiforme
- a type of brain cancer that is almost always fatal. Glioblastoma is one of three cancers that will be analysed in the atlas's US\$100-million three-year pilot programme, which is funded jointly by the NCI and the NHGRI. The other two diseases being analysed are lung and ovarian cancers.

The pilot aims to analyse at least 500 samples of each cancer. But this February, when scientists started to retrieve tissue samples from the bank, "we started realizing the scene wasn't as rosy as we had hoped", says Carolyn Compton, director of biorepositories and biospecimen research at the NCI.

So far, the project has analysed fewer than

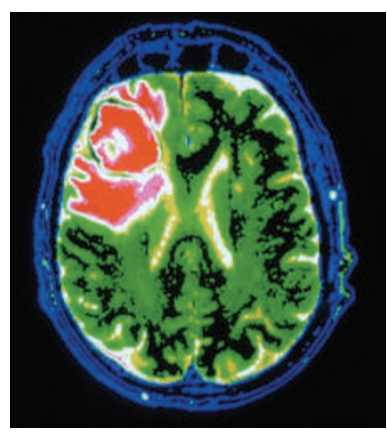

Deadly diseases: the fatal brain cancer glioblastoma can be hard to sample. half the number expected because about half of the samples at the MD Anderson bank haven't met the project's stringent quality tests, according to cancer geneticist Ronald DePinho from Harvard Medical School in Boston, Massachusetts, who is co-chair of the atlas's external scientific committee.

Compton and other scientists say this problem isn't unique to the MD Anderson tumour bank. Variable sample quality is a concern with all tissue banks, scientists say, because every bank has its own standards, and samples aren't usually checked for quality until someone needs them for a project.

"We haven't had the large number of samples we expected," says Lynda Chin, a cancer geneticist at the Dana-Farber Cancer Institute in Boston, Massachusetts, and co-head of one of the atlas's seven Cancer Genome Characterization Centers. "But this is the reality of the limitations of the existing tissue banks."

The Cancer Genome Atlas set high standards for its samples to ensure high-quality data. All the samples included in the project must have at least $80 \%$ viable cells, because the project is analysing DNA and RNA only from live cells. The samples also have to be quite large — weighing at least 200 milligrams — 
because the tissue has to be shared between the many analysis centres involved in the project.

The high standards are part of the reason that the project stumbled with the glioblastoma samples. Glioblastoma tumours tend to be spread throughout the brain, and must by definition contain necrotic, or dead, tissue. So scientists expected that some tumours from the MD Anderson bank would contain too much necrotic tissue to meet their criteria - but not this many.

The failure of so many samples has prompted the Cancer Genome Atlas to expand its criteria to admit brain-cancer samples with more necrotic tissue. It has also started to take samples from brain tumour banks at the Henry Ford Health System in Detroit, Michigan, and the University of California, San Francisco.

Compton says that the lung and ovarian cancer projects shouldn't have the same problems as the one for glioblastoma, because those tumours tend to be larger. She still hopes that the pilot project will complete its work in the scheduled three years.

But changing the criteria for glioblastoma samples won't solve the bigger problems with tissue banking. Foremost among them is how the procedures used in tissue banking affect the nucleic acids and proteins in the stored samples. For instance, it's not clear how anaesthesia affects gene expression during surgery to remove tumours, Compton says. That could mean that signatures gleaned from banked tissues might just be by-products of procedures used in surgery and storage - not markers of disease processes. "The state of the science right now is pathetic," Compton says.

Because the science is so poor, the NCI has decided, for the first time, to fund studies on biospecimen banking. On 28 June, Compton is scheduled to present the agency's biospecimen research plan to its board of scientific advisers. If it is approved, the NCI will award scientists money to study how collection and banking processes affect the nucleic acids and proteins embedded within tissue samples.

The NCI is also working with research agencies around the world to try to encourage tissue banks everywhere to adopt uniform standards. Researchers in many countries are grappling with the same problem. The International Agency for Research on Cancer, a World Health Organization body based in Lyon, France, with 20 member states, is also trying to address it.

In the meantime, DePinho insists that the Cancer Genome Atlas is doing well for a new venture of its scope. "This is an extraordinarily difficult project, so these hiccoughs at the embryonic stage are to be expected," he says. Erika Check

\section{Geophysicists combine forces}

\begin{abstract}
An ambitious programme aimed at freeing up Earthscience data for researchers and educators worldwide will be launched next week at the quadrennial meeting of the International Union of Geodesy and Geophysics in Perugia, Italy. It is one of several efforts by geoscientists to improve access to geophysical data on the web.

Called the Electronic Geophysical Year (eGY), the programme has been

of Colorado in Boulder and an eGY organizer. "We hope to build layers of software so anyone can display and integrate data in different forms." On 12-15 June, around 75 researchers from around the world attended the Virtual Observatories in Geosciences conference in Denver, Colorado, to plot this course.

A case in point, says Jeffrey Love, a geomagnetist at the US Geological Survey office in Denver, are records of Earth's magnetic field that extend
\end{abstract} organized by a broad range of researchers and organizations and will promote the creation of virtual observatories to make geophysical data easier to find and use. It takes its inspiration from the fiftieth anniversary of the 1957 International Geophysical Year, which was the first concerted effort to understand the Earth as a physical system.

Sharing and transferring data is much easier than it was during the original International Geophysical Year. But because different research groups often have data stored in incompatible formats, researchers can't always combine the various sources for study. Efforts to transfer historical data languishing in archives from deteriorating paper to accessible digital formats are piecemeal and require prioritization.

One of eGY's goals is to overcome such hurdles, in part through the use of virtual observatories that will serve as clearinghouses for scientific collections. "This is the forefront of information technology: to standardize computer-language syntax," says William Peterson, a physicist at the University

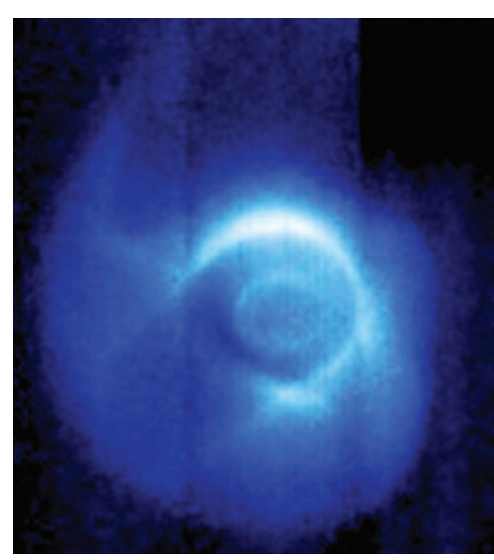

Force field: Earth's magnetosphere could shed light on magnetic storms.

back to the nineteenth century. Decades-old data originally gathered to help marine navigation at labs in Maryland, Hawaii and Alaska are now of interest to scientists studying magnetic storms in Earth's magnetosphere that occur as a result of solar activity. "It is a daunting task," says Love, "making sure people know what they have and should save."

Other international efforts are aimed at collecting new data. One part of the current International Heliophysical Year is a concerted effort to extend low-cost datacollection systems to developing nations. In Africa, for instance, 35 nations have agreed to the installation of special Global Positioning

System pods. These use the signals from navigation satellites to measure electron density in the ionosphere (where the atmosphere meets space). Such monitoring is widespread in the United States, Europe and Latin America, but data for Africa are weak, says Joseph Davila, a physicist at NASA's Goddard Space Flight Center in Greenbelt, Maryland, who is leading the effort. Last week, Davila was in Libya helping to install a radio receiver at the University of Sheba, south of Tripoli, as part of AWESOME (Atmospheric Weather Electromagnetic System for Observation, Modeling and Education), another ionospheric monitoring project.

In 2008, the United

Nations-sponsored Year of Planet Earth will be looking at similar efforts to further its goal of promoting "Earth Sciences for Society". Eduardo de Mulder of the Geological Survey of the Netherlands in Utrecht, a leader on the Planet Earth project, says the organization is trying to raise at least US $\$ 5$ million to fund international efforts that would include 60 nations. Scientists are applying for grants from this pool of funds, with the first awards expected late this year.

Among the project's main efforts will be an annotated geological map of the world, onegeology.com, that would provide access to all sorts of data. "It would be a living process," says de Mulder, "with the public and governments using the Earth science information to make better policy decisions." Rex Dalton 